\title{
CHANGE OF DYNAMIC CONTACT ANGLE OF A DROP SPREADING OVER COPPER SURFACE
}

\author{
D.V. Feoktistov ${ }^{1, a}$, E. G. Orlova ${ }^{2}$, A. G. Islamova ${ }^{2}$ \\ ${ }^{1}$ S. S. Kutateladze Institute of Thermal Physics, Siberian Branch, Russian Academy of Sciences, 630090 \\ Novosibirsk, Russia \\ ${ }^{2}$ National Research Tomsk Polytechnic University, 634050 Tomsk, Russia
}

\begin{abstract}
This work presents the comparison between the change of a dynamic contact angle during drop spreading over copper surfaces obtained in the experiment and calculated by using empirical correlations (Bracke et al., Jiang et al., Seebergh et al.). It is found that these correlations are applicable for the case of drop spreading over a smooth surface or over a rough surface into the low capillary number region $\left(2.5 \cdot 10^{-7}\right)$. Dynamic contact angles obtained experimentally increase with increasing capillary number, besides it increases significantly on more rough surfaces. However the calculated values of angles do not depend on $\mathrm{Ca}$.
\end{abstract}

\section{Introduction}

To create an energy-efficient heat exchanger for high heat flow removal (up to $1000 \mathrm{~W} / \mathrm{cm}^{2}$ ) from a source with small linear dimensions, it is necessary to develop the hydrodynamics of gas-liquid flows in mini-systems and mini-channels [1-3]. Heat transfer agent in such system is a liquid film with a few millimeters in thickness. Its movement and evaporation depends on wetting. Physical mechanisms of wetting can be described by molecular-kinetic theory or hydrodynamics. Accordingly, wetting is considered either in terms of the kinetics of molecular processes occurring in a contact line [4-7] or the effect of the viscous stress on a contact angle change (dynamic contact angle change) while spreading $[8,9]$.

A dynamic contact angle (DCA) $\theta_{d}$ characterizing wetting process is a function of contact line speed $U_{C}$ (or capillary number $\mathrm{Ca}$ ) and equilibrium contact angle $\theta_{0}$ [10]. Nowadays there is no universal expression to relate contact angle with contact line speed [11,12].

One of the first empirical correlations of DCA from $C a$ and $\theta_{0}$ [11] was given for water on glass surface:

$$
\frac{\cos \theta_{0}-\cos \theta_{d}}{\cos \theta_{0}+1}=4.96 \cdot C a^{0.702}
$$

Equation (1) is applicable for values of the capillary number less than 0.01 .

DCA is experimentally found to decrease linearly and to be proportional to $\mathrm{Ca}^{0,5}[12]$ :

${ }^{\text {a } C o r r e s p o n d i n g ~ a u t h o r: ~ f d v @ t p u . r u ~}$

This is an Open Access article distributed under the terms of the Creative Commons Attribution License 4.0, which permits unrestricted use, distribution, and reproduction in any medium, provided the original work is properly cited. 


$$
\frac{\cos \theta_{0}-\cos \theta_{d}}{\cos \theta_{0}+1}=2 \cdot C a^{0.5}
$$

Investigations [12] were conducted on smooth and rough polyethylene and polyethylenetherephthalate surfaces. Aqueous glycerin solution, aqueous ethyleneglycol solution and oil were used as working liquids.

The empirical correlation at low capillary number for polar and nonpolar liquids (silicon oil, water, bromoform, methylene iodide, diethylene dioxide) on polyethylene substrates has been obtained in [13]:

$$
\frac{\cos \theta_{0}-\cos \theta_{d}}{\cos \theta_{0}+1}=4.47 \cdot C a^{0.42}
$$

It is noteworthing that equations (1) - (3) have the same functional form [12]:

$$
H=\frac{\cos \theta_{0}-\cos \theta_{d}}{\cos \theta_{0}+1}=A C a^{B}
$$

Equations (1) - (3) were obtained after conducting the experiments on the substrates made of glass, polyethylene, polymer materials. Traditionally, metals with high thermal conductivity (copper, brass, aluminum) are used for manufacturing the heat exchange systems with small linear dimensions. However, there are no correlations of DCA from $C a$ and $\theta_{0}$ for drop spreading over these materials, which can be applied for modeling the high energy efficient heat exchange systems.

The purpose of this work is to obtain empirical correlations of DCA from capillary number and equilibrium contact angle under the conditions of distilled water drop spreading over the copper surfaces.

\section{Research method}

Experimental investigations were conducted on the setup presented in Fig.1. The operating principle is given in detail in [14].

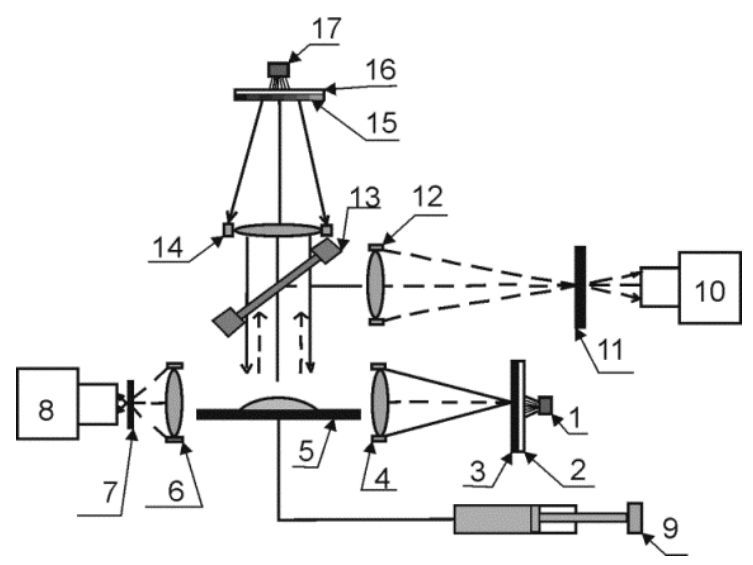

Figure 1. Schematic diagram of an experimental setup: 1, 17 - light source; 2, 16- ground glass; 3, 7, 11 transparent shield with an opening; 4, 14 - collimating lens; 5 - substrate; 6 - condensing lens; 9 - syringe pump; 8,10 - high-speed video camera; 12 - Schlieren lens; 13 - beam splitter; 15 - coding filter

Three copper substrates with different surface roughness were used in the experiment. The substrates are disks ( $54 \mathrm{~mm}$ in diameter and $4 \mathrm{~mm}$ thick) with a centered through opening ( $2 \mathrm{~mm}$ in diameter). The rough surfaces of samples No. 2 and No. 3 are obtained by bombarding a smooth surface with $\mathrm{Al}_{2} \mathrm{O}_{3}$ particles of 10 and 100 microns. The surface of sample No. 1 was not bombarded.

The surface profile and roughness parameter (arithmetic average roughness $\mathrm{Ra}$ ) are obtained on the profilometer "Micro Measure 3D station" (Table 1). 
According to results of a preliminary experiment, the values of influencing factors were defined (Table 1).

Table 1. The main influencing factors

\begin{tabular}{|c|c|}
\hline Parameter & Value \\
\hline Drop volume, $\mathrm{ml}$ & 0.3 \\
\hline Volume flow rate of liquid, $\mathrm{ml} / \mathrm{s}$ & 0.08 \\
\hline Roughness parameter of surface & Sample No.1 (flexible copper) $-\mathrm{Ra}=0.591 ;$ \\
$\mathrm{Ra}, \mu \mathrm{m}$ & Sample No.2 (copper) $-\mathrm{Ra}=5.190 ;$ \\
& Sample No.3 (copper) $-\mathrm{Ra}=6.210 ;$ \\
\hline Wetting liquid & Nondeaerated distilled water \\
\hline
\end{tabular}

\section{Results and discussion}

Figure 2 presents typical dependences obtained from the results of experimental series and also from calculations by using equations (1) - (3).

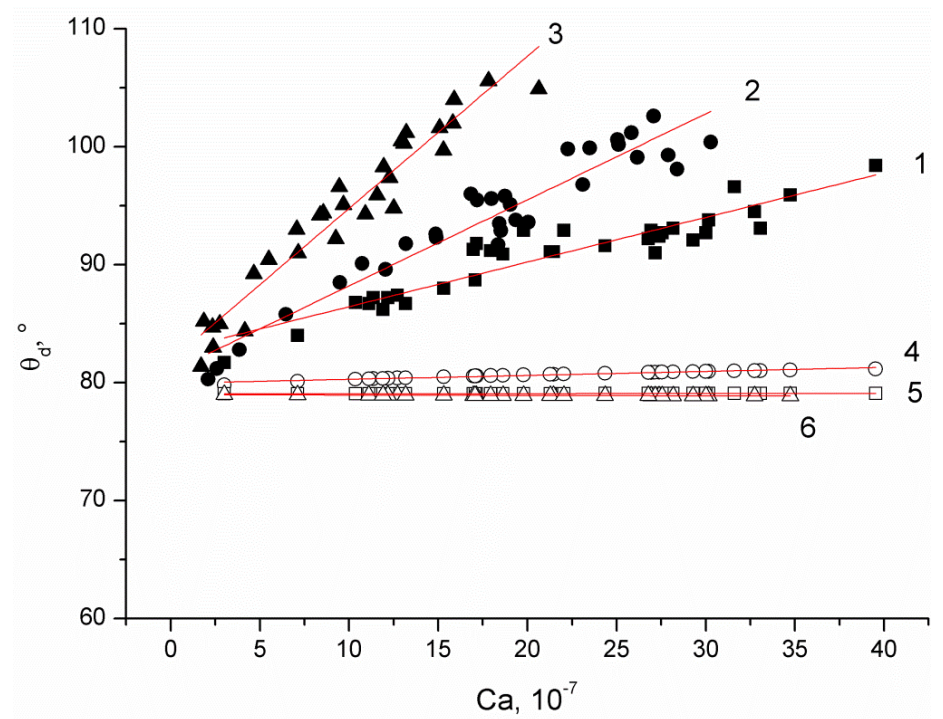

Figure 2. DCA versus capillary number. Experimental results: 1 - sample No $1 ; 2$ - sample No 2;3-sample No 3. Computational results by using equations obtained by: 4 - Seebergh et al., eq. (1); 5 - Jiang et al. eq. (2); $6-$ Bracke et al. eq. (3)

It is noteworthy that the empirical correlations (1) - (3) do not take into account surface roughness (relatively smooth materials, such as glass, polymers were used in the experiments).

According to results of DCA calculation by using equations (1) - (3) (Fig.2), it is found that the dynamic contact angle (during drop spreading over rough copper surfaces) does not depend on the capillary number. And the divergence in results obtained from these three eq. (1) - (3) is more than $3 \%$. However, after analyzing results of the experimental series, it has been found that $\theta_{d}$ increases as the capillary number increases. Moreover, $\theta_{d}$ increases significantly on surfaces with high roughness $(\mathrm{Ra})$. This result can be explained by an increase of the friction force over the surface tension with increasing capillary number. During drop spreading over the surface, liquid on the three-phase contact line pins on micro asperities of the substrate.

The empirical correlations (1) - (3) are applicable in the case of liquid drop spreading over the smooth surfaces or over the rough surfaces into the low capillary number region (up to $2,5 \cdot 10^{-7}$ ). After 


\section{MATEC Web of Conferences}

comparing the results of experiments and calculations (Fig. 2) in these values of $\mathrm{Ca}$, the divergence of $\theta_{d}$ was not more than $2 \%$.

The dependence on the ratio of $\cos \theta_{d}$ and $\cos \theta_{0}$ from capillary number is calculated by using experimental results and plotted in Fig.3. Obtained function is analogous to Eq. (4) [12].

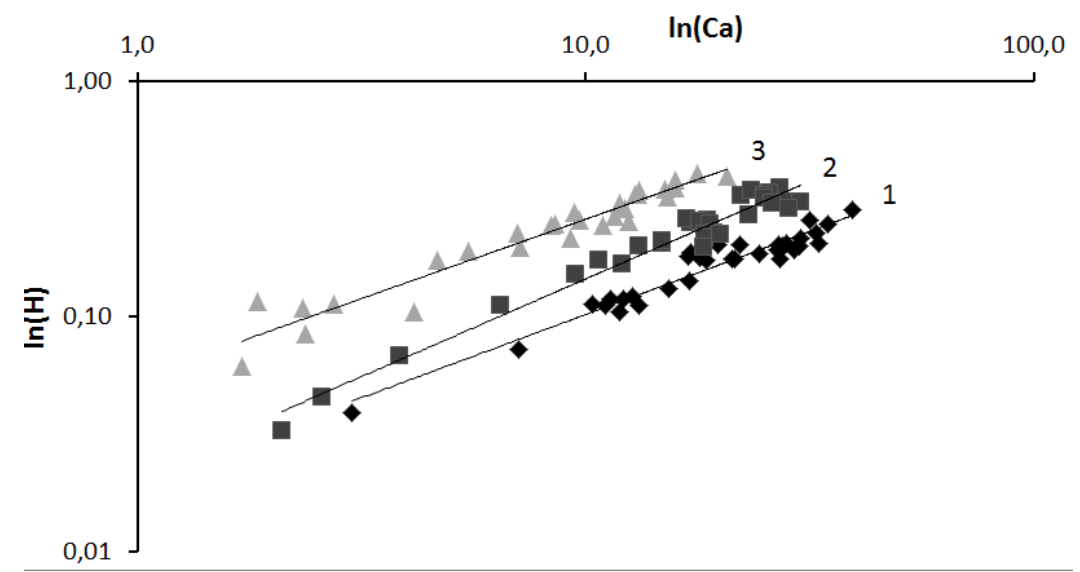

Figure 3. Ratio of $\cos \theta_{d}$ and $\cos \theta_{0}$ versus $C a$ for substrates: 1 - sample No $1 ; 2$ - sample No 2; 3 - sample No 3

The curves in Fig. 3 are approximated by a power function:

$$
\begin{array}{ll}
\text { sample No 1: } & H=\frac{\cos \theta_{0}-\cos \theta_{d}}{\cos \theta_{0}+1}=0.02 \mathrm{Ca}^{0.7} ; \\
\text { sample No 2: } & H=\frac{\cos \theta_{0}-\cos \theta_{d}}{\cos \theta_{0}+1}=0.0214 \mathrm{Ca}^{0.83} ; \\
\text { sample No 3: } & H=\frac{\cos \theta_{0}-\cos \theta_{d}}{\cos \theta_{0}+1}=0.0549 \mathrm{Ca}^{0.67}
\end{array}
$$

The exponent $\mathrm{B}$ characterizes the slope angle of the dependences presented in Fig.3. Comparing eq. (5) - (7) it should be noted that B does not depend on the arithmetic average roughness of the surfaces. However the type of dependences $\mathrm{H}=\mathrm{f}(\mathrm{Ca})$ is almost identical.

Coefficient A depends on the roughness: with increasing the roughness $\mathrm{A}$ increases.

\section{Conclusion}

The following results have been obtained after conducting the experimental investigations of distilled water drop spreading over the copper surface:

- DCA obtained experimentally increases with raising the capillary number. Moreover, $\theta_{d}$ increases significantly on surfaces with high roughness.

- DCA calculated by using the empirical correlations (Bracke et al., Jiang et al., Seebergh et al.), does not depend on the capillary number.

- It was found that the empirical correlations obtained by Bracke et al., Jiang et al., Seebergh et al. are applicable in the case of liquid drop spreading over the smooth surfaces or over the rough surfaces into the low capillary number region (up to $2,5 \cdot 10^{-7}$ ).

This work was carried out with the financial support from the grant of the Russian Scientific Fond (project No. 15-19-10025). 


\section{References}

1. E. A. Chinnov, O. A. Kabov, Technical physics letters, 37, 921 (2011).

2. Yu. V. Lyulin, O.A. Kabov, Technical physics letters, 39, 795 (2013).

3. V.E. Nakoryakov, S. Y. Misyura, S. L. Elistratov, R. A. Dekhtyar, J Eng Thermophys Rus, 23, 257 (2014).

4. T.D. Blake, K.J. Ruschak, Wetting: Static and Dynamic Contact Lines, Liquid Film Coating (Chapman and Hall, London, 1997).

5. E. Ruckenstein, C. S. Dunn, J. Colloid Interface Sci, 59, 135 (1997).

6. J. H. Snoeijer, B. Andreotti, Annu. Rev. Fluid Mech, 45, 269 (2013).

7. A.Ye. Rednikov, P. Colinet, Langmuir, 27, 1758 (2011).

8. E. Ya. Gatapova, A. A. Semenov, D. V. Zaitsev, O. A. Kabov, Colloids Surf., A., 441, 776 (2014).

9. R. Chebbi, J. Colloid and Interface Science, 300, 688 (2006).

10. J. E. Sprittles, Dynamic wetting/dewetting processes in complex liquid-solid systems, $\mathrm{phD}$ thesis (University of Birmingham, Birmingham, 2010).

11. T. S. Jiang, S. G. Oh, J. C. Slattery, J. Colloid Interface Sc, 69, 74 (1979).

12. M. Bracke, F. De Voeght, P. Joos, Progr. Colloid Pol. Sc, 79, 142 (1989).

13. J. E. Seebergh, J. C. Berg, Chem. Eng. Sc, 47, 4455 (1992).

14. E. G. Orlova, G. V. Kuznetsov, D. V. Feoktistov, EPJ Web of Conferences, 82, 1 (2015). 